\title{
Clinical safety of total glucosides of paeony adjuvant therapy for rheumatoid arthritis treatment: a systematic review and meta- analysis
}

Bin Liu ${ }^{1 \dagger}$, Xiang Meng ${ }^{1+}$, Yanfang Ma ${ }^{2,3,4 \dagger}$, Huizhen Li ${ }^{1}$, Yuqi Liu' ${ }^{1}$, Nannan Shi ${ }^{1}$, Yaolong Chen ${ }^{2,3,4^{*}}$, Yanping Wang ${ }^{1 *}$ and Cheng Lu ${ }^{1 *}$ (D)

\begin{abstract}
Background: Total glucosides of paeony (TGP), an active compound extracted from the roots of Paeonia lactiflora Pallas, has been increasingly used as the adjunctive therapy for rheumatoid arthritis (RA) patients. Though TGP could mitigate the unanticipated adverse effects during the conventional treatment of RA, high-quality evidencebased meta-analysis data on this subject are still insufficient. The objective of this study is to evaluate the clinical safety of TGP adjuvant therapy in the RA treatment.

Methods: PubMed, EMBASE, Web of Science, China Network Knowledge Infrastructure (CNKI), SinoMed and WanFang Data were retrieved for randomized controlled trials (RCTs) and cohort study about TGP adjuvant therapy in patients with RA up to 28 January 2021. Literatures with eligibility criteria and information were screened and extracted by two researchers independently. The RevMan5.3 software was used for data analysis with effect estimates as risk ratio (RR) with 95\% confidence interval (CI).

\footnotetext{
*Correspondence: chenyaolong21@163.com; wangyanping4816@163.com; IV_cheng0816@163.com

${ }^{\dagger}$ Bin Liu, Xiang Meng and Yanfang Ma contributed equally to this work.

${ }^{2}$ Evidence-Based Medicine Center, School of Basic Medical Sciences, Lanzhou University, Lanzhou, China

${ }^{1}$ Institute of Basic Research in Clinical Medicine, China Academy of Chinese Medical Sciences, Beijing, China

Full list of author information is available at the end of the article
}

(c) The Author(s). 2021 Open Access This article is licensed under a Creative Commons Attribution 4.0 International License, which permits use, sharing, adaptation, distribution and reproduction in any medium or format, as long as you give appropriate credit to the original author(s) and the source, provide a link to the Creative Commons licence, and indicate if changes were made. The images or other third party material in this article are included in the article's Creative Commons licence, unless indicated otherwise in a credit line to the material. If material is not included in the article's Creative Commons licence and your intended use is not permitted by statutory regulation or exceeds the permitted use, you will need to obtain permission directly from the copyright holder. To view a copy of this licence, visit http://creativecommons.org/licenses/by/4.0/ The Creative Commons Public Domain Dedication waiver (http://creativecommons.org/publicdomain/zero/1.0/) applies to the data made available in this article, unless otherwise stated in a credit line to the data. 


\begin{abstract}
(Continued from previous page)
Results: A total of 39 studies involving 3680 RA participants were included. There were 8 comparisons: TGP plus methotrexate (MTX) therapy versus MTX therapy, TGP plus leflunomide (LEF) therapy versus LEF therapy, TGP plus MTX and LEF therapy versus MTX plus LEF therapy, TGP plus tripterygium glycosides (TG) therapy versus TG therapy, TGP plus meloxicam (MLX) therapy versus MLX therapy and TGP plus sulfasalazine (SSZ) therapy versus SSZ therapy, TGP plus iguratimod (IGU) therapy versus IGU therapy, TGP plus prednisone acetate tablets (PAT) therapy versus PAT therapy. The meta-analysis results showed that the occurrence of hepatic adverse effect $(R R=0.31,95 \%$ $\mathrm{Cl}=0.23-0.41, P<0.00001)$ and leukopenia $(\mathrm{RR}=0.41,95 \% \mathrm{Cl}=0.26-0.66, P=0.0002)$ in TGP adjuvant therapy was significant decreased compared with non-TGP therapy. However, only TGP plus LEF therapy $(R R=0.22,95 \% \mathrm{Cl}=$ $0.08-0.60, P=0.003)$ and TGP plus MTX and LEF therapy (RR $=0.31,95 \% \mathrm{Cl}=0.22-0.42, P<0.00001)$ had statistical difference in the subgroups of hepatic adverse effect. In leukopenia, TGP plus MTX and LEF therapy (RR $=0.47,95 \%$ $\mathrm{Cl}=0.25-0.87, P=0.02$ ) had statistical difference.

Conclusions: This meta-analysis indicated that TGP adjuvant therapy might alleviate the incidence of hepatic adverse effect and leukopenia for the RA treatment compared to non-TGP therapy. The clinical safety of TGP adjuvant therapy warrant further investigation in experimental studies.
\end{abstract}

Keywords: Rheumatoid arthritis, Total glucosides of paeony, Adjuvant therapy, Clinical safety, Systematic review, Meta-analysis

\section{Background}

Rheumatoid arthritis (RA) is a chronic autoimmune disease with an increasing global prevalence, characterized by chronic synovial inflammation, cartilage and joint erosion, pannus formation, joint abnormalities and ankylosis [1]. At present, four types of drugs including nonsteroidal anti-inflammatory drugs, disease-modifying anti-rheumatic drugs, glucocorticoid and biological agents are commonly used for the RA treatment $[2,3]$. However, some unanticipated adverse effects, such as gastrointestinal effects, skin effects, hepatotoxicity, and neurological symptoms, occur occasionally during the long therapeutic procedure [4-7]. In clinical practice, adjuvant drug treatments have been often applied to reduce adverse effects [8] and many patients are also willing to approve such adjuvant therapy [9].

In classical Chinese herbal textbooks and the Pharmacopoeia of China, Paeonia lactiflora Pallas is often referred to as a holy drug to protect the liver [10]. Traditional Chinese medicine posits that the liver holds blood, and modern medical research has confirmed that the liver is not only an important metabolic organ, but also an immune organ. The liver is rich in natural immune cells, and its unique immune-cell composition plays an important role in the formation of its functional characteristics $[11,12]$. As an active compound extracted from the roots of Paeonia lactiflora Pallas, total glucosides of paeony (TGP) has been increasingly used as the adjunctive therapy for RA patients [13]. TPG contains more than fifteen monoterpene glycosides, such as paeoniflorin, albiflorin, oxypaeoniflorin, benzoylpaeoniflorin, benzoyloxypeoniflorin [14]. With the development of chemical component separation technology and analysis technology, more and more new monoterpene glycoside components in TGP are separated and analyzed. While TGP has good anti-inflammatory and immunosuppressive effects $[15,16]$, it also has been confirmed to be hepatoprotective [17]. In the meantime, TGP combined with methotrexate (MTX) and leflunomide (LEF) might be more effective against RA, showing a reduced erythrocyte sedimentation rate, $\mathrm{C}$-reactive protein level and rheumatoid factor. Besides, hepatotoxicity has also been decreased significantly in the TGP adjuvant therapy [18]. Though TGP could mitigate the unanticipated hepatotoxicity during the conventional treatment of RA, high-quality evidence-based meta-analysis data on clinical safety of TGP adjuvant therapy are still insufficient. This study aims to evaluate the clinical safety of TGP adjuvant therapy in the RA treatment.

\section{Methods \\ Protocol and registration}

This meta-analysis had been registered on PROSPERO of the Centre for Reviews and Dissemination (NO: CRD42018118519).

\section{Eligibility and exclusion criteria}

Eligibility criteria were as following: (1) participants were diagnosed with RA based on the criteria revised by the American College of Rheumatology in 1987 or the ACR/ European League Against Rheumatism in 2010; (2) The trial was claimed to be a randomized controlled trial (RCT) or cohort study comparing the TGP adjuvant therapy to non-TGP therapy; (3) the language of studies was limited to English or Chinese; (4) predefined outcome: clinical adverse effect, including gastrointestinal adverse effect, cutaneous adverse effect, hepatic adverse effect, leukopenia and nervous system adverse effect 
based on the report of National Medical Products Administration, literatures and clinical physicians' opinion.

Exclusion criteria were as following: (1) participants in studies with other serious diseases; (2) reviews and trials published only as abstracts; (3) there are additional treatment factors in the control group and/or the combination group; (4) the language was not written in English or Chinese.

\section{Search strategy}

To assess the clinical safety of TGP adjuvant therapy for RA, we searched 6 databases including PubMed (19662021), EMBASE (1974-2021), Web of Science (19802021), China Network Knowledge Infrastructure (CNKI) (1979-2021), SinoMed (1978-2021) and WanFang Data (1997-2021) from inception to 28 January 2021. The search strategies were as follows: "Rheumatoid Arthritis" OR "Caplan Syndrome" OR "Rheumatoid Nodule" OR "Rheumatoid Vasculitis" OR "Sjogren's Syndrome" OR "Adult-Onset Still's Disease" AND "total glucosides of paeonia" OR "total glucosides of paeony" OR "bai shao zong gan" AND "Adverse Reaction" OR "Toxicity" OR "Side Effect" OR "Toxic Reaction". Various combinations of the keywords were applied and the search strategy amalgamated MeSH terms with text words search. The detailed search strategy for each electronic database is available in Additional file 1.

\section{Study selection and data extractions}

The titles and abstracts of the searched results were assessed by two authors independently. Then the full texts of potentially eligible studies were screened to identify the final included studies. The standard form was pre-designed for this systematic review. The extracted data were as follows: study characteristics (authors, title, etc.), methodological information (randomization, allocation concealment, blinding, and follow-up, selective outcome reporting), patient characteristics (number of patients, age, gender, etc.), intervention, control, and outcomes. Any disagreements were discussed or sought a third opinion.

\section{Assessment of risk of bias in included studies}

Two authors used the tools developed by Higgins and Green in the Cochrane Systematic Review Intervention Handbook to assess the risk of bias in inclusion in studies independently. The following risk of bias: selection bias (random sequence generation and allocation concealment), performance bias (blinding of participants and personnel), detection bias (blindness of researchers performing outcome evaluation), attrition bias (incomplete outcome data), reporting bias (selective reporting) and other sources of bias were assessed. Meanwhile, "low risk", "high risk" or "unclear risk" judgment had been provided for each aspect of the risk of bias.

\section{Statistical analysis}

Data were aggregated using risk ratio (RR) with 95\% confidence intervals (CI) for binary outcomes. Revman 5.3 Software was used from the Cochrane Collaboration for data analyses. Meta-analysis was performed if the trials had a good homogeneity on study design, participants, interventions, control, and outcome. Statistical heterogeneity was tested by examining both the Chisquared test and the Isquared statistic $\left(I^{2}\right)$, which means that an $I^{2}$ is greater than $50 \%$ and $P$ is less than or equal to 0.1 indicating the possibility of statistical heterogeneity and employing random-effects model. If there was no statistically significant heterogeneity between studies in the meta-analysis, the fixed effect model was adopted. Funnel plots and Egger's test were used to assess the publication bias if more than 10 studies tested the same outcome in one meta-analysis.

\section{Results}

\section{Search results}

There were 697 articles identified by literature search: SinoMed $(n=184)$, CNKI $(n=127)$, WanFang Data $(n=310)$, PubMed $(n=24)$, Web of Science $(n=32)$, EMBASE $(n=20)$. NoteExpress was used to conduct duplicate checking and ultimately selected 200 papers. After reading through the full article, existence of wrong data $(n=134)$ and absence of adverse effect data $(n=$ 27) were excluded. In the end, 39 articles [19-57] in total were included for the meta-analysis (Fig. 1). We also tried to get unpublished studies from databases of relevant clinical trials, however, there were no eligible studies.

\section{Study characteristics}

These 39 included trials, which involved 3680 RA participants, were all conducted in mainland China. They were published from 2005 to 2020 . There were 1874 and 1806 patients were enrolled in the TGP adjuvant therapy groups and the non-TGP therapy groups, respectively. There were 8 comparisons: TGP plus methotrexate (MTX) therapy versus MTX therapy [20, 21, 31-33, 43, $45,48,50-53,55,56]$, TGP plus leflunomide (LEF) therapy versus LEF therapy [34, 37, 40, 47, 49, 54], TGP plus MTX and LEF therapy versus MTX plus LEF therapy [22-29, 35, 38, 39, 42, 44, 46], TGP plus tripterygium glycosides (TG) therapy versus TG therapy [57], TGP plus meloxicam (MLX) therapy versus MLX therapy [36], TGP plus sulfasalazine (SSZ) therapy versus SSZ therapy [41], TGP plus iguratimod (IGU) therapy versus IGU therapy [30] and TGP plus prednisone acetate 




Fig. 1 Flow diagram illustrating the process of identifying articles for selection

tablets (PAT) therapy versus PAT therapy [19]. The detailed characteristics are presented in Table 1.

\section{Risk of bias of included studies}

Thirty-seven trials [19-26, 29-57] were RCTs, 2 trials $[27,28]$ were cohort study and the baseline characteristics of each trial were comparable. Four trials [21, 28, 33, 34] had a high risk of bias by using the wrong random sequence generation and seven trials $[20,29,35,36,40$, 43,57 ] had a low risk of bias because of their generating random numbers by using the random number table or centralized randomization. Two trials [51, 52] used blinding of participants and personnel. One trial [52] had a low risk of bias on account of it was double-blind and reported the blinding of outcome assessment. Two trials $[34,44]$ had a high risk of bias in selective reporting. All trials had an unclear risk of bias allocation concealment and blinding of outcome assessment because of incomplete outcome data (Fig. 2).

\section{Effects of interventions}

Our analysis revealed that TGP adjuvant therapy could decrease the incidence of hepatic adverse effect $(R R=$ $0.31,95 \% \mathrm{CI}=0.23-0.41, \quad P<0.00001$ ) (Fig. 3) and leukopenia $(\mathrm{RR}=0.41,95 \% \mathrm{CI}=0.26-0.66, P=0.0002)$ (Fig. 4) compared with non-TGP therapy. However, there were no statistical difference of gastrointestinal adverse effect $(\mathrm{RR}=1.05,95 \% \mathrm{CI}=0.90-1.23, P=0.54)$ (Fig. 5), cutaneous adverse effect $(\mathrm{RR}=0.61,95 \% \mathrm{CI}=$ $0.36-1.02, P=0.06$ ) (Fig. 6) and nervous system adverse effect $(\mathrm{RR}=0.79,95 \% \mathrm{CI}=0.42-1.15, P=0.48)$ (Fig. 7) between TGP adjuvant therapy and non-TGP therapy.

22 studies evaluated the hepatic adverse effect with 1241 patients in the TGP adjuvant therapy group and 


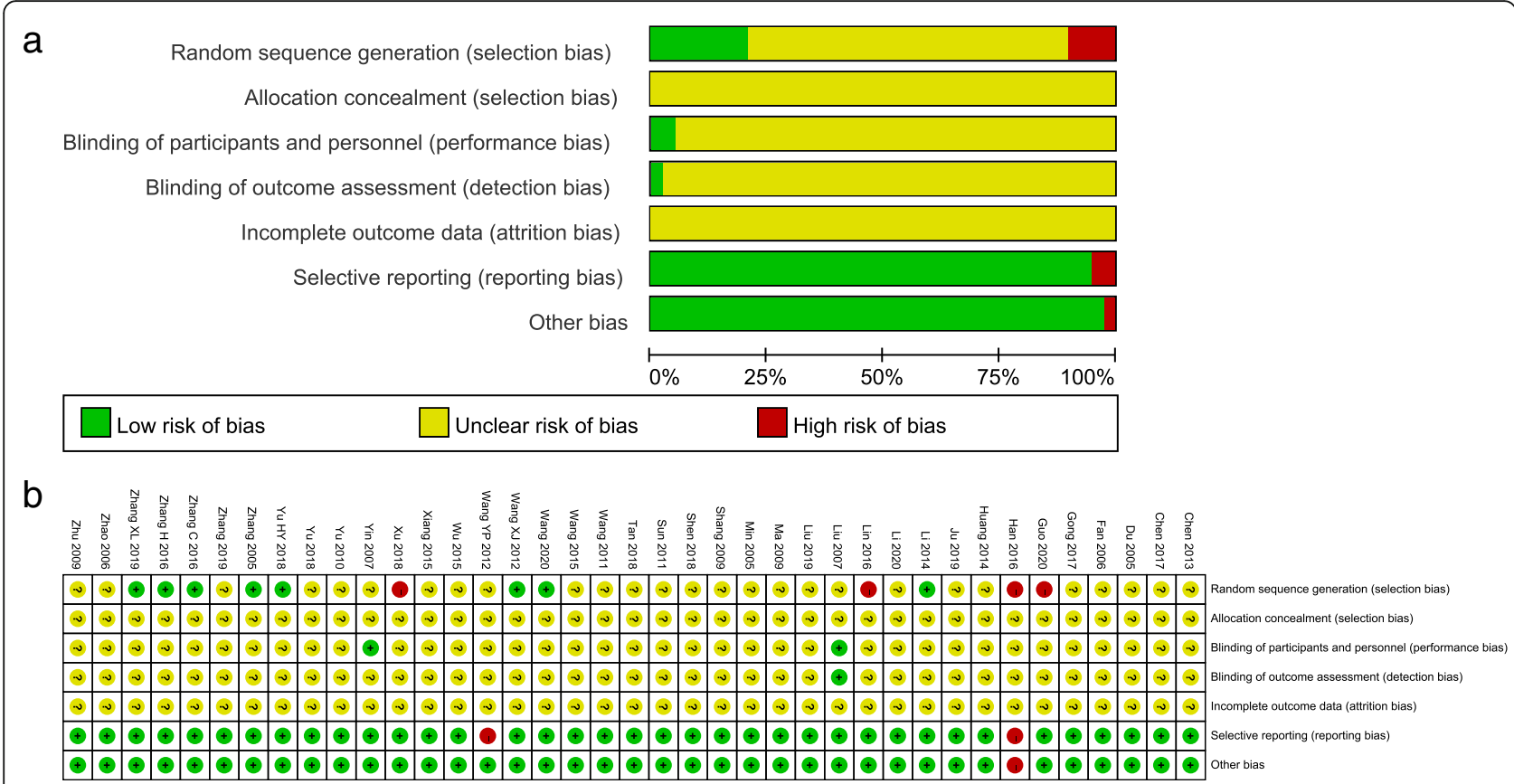

Fig. 2 Risk of bias summary (a) and Risk of bias graph (b)

1185 patients in the non-TGP therapy group. Although TGP adjuvant therapy can decrease the incidence of hepatic adverse effect, only TGP plus LEF therapy $(\mathrm{RR}=$ $0.22,95 \% \mathrm{CI}=0.08-0.60, P=0.003)$ and TGP plus MTX and LEF therapy ( $\mathrm{RR}=0.31,95 \% \mathrm{CI}=0.22-0.42, P<$ 0.00001) had statistical difference in the subgroups. Meanwhile, no statistical difference was found in the following four comparisons of gastrointestinal adverse effect, nervous system adverse effect and cutaneous adverse effect: (1) TGP plus MTX versus MTX; (2) TGP plus LEF versus LEF; (3) TGP plus MTX and LEF versus MTX plus LEF; (4) TGP plus MLX/SSZ/IGU/PAT versus MLX/SSZ/IGU/PAT.

\section{Sensitivity analysis}

Sensitivity analysis was implemented to evaluate the results and we found that there was no significant change, suggesting that the sensitivity was low and the results were more stable.

\section{Discussion}

This systematic review aims to assess the clinical safety of TGP adjuvant therapy in the RA treatment. 39 trials involving 3681 RA patients were included in this review with language restrictions in both Chinese and English. Clinical adverse effect including gastrointestinal adverse effect, cutaneous adverse effect, hepatic adverse effect, leukopenia, and nervous system adverse effect were analyzed in TGP adjuvant therapy and non-TGP therapy. The meta-analysis results signified that the occurrence of hepatic adverse effect and leukopenia in TGP adjuvant therapy was significant decreased. However, no statistical significance was found in subgroup analysis of gastrointestinal adverse effect, nervous system adverse effect and cutaneous adverse effect, the reason for this might be the sample size was small and the quality of methodologies used in the included studies was poor.

Hepatic adverse effect is one of the main adverse effects of MTX and LEF in the treatment of RA. Elevated levels of alanine transaminase (ALT) and aspartate transaminase (AST) in serum suggest the architecture of hepatic cell may be injured. Although the reversibility of mild liver enzyme elevations in a clinical trial setting is reassuring, the potential for increased hepatic toxicity with the use of MTX and LEF combination should be recognized [58, 59]. Previous study demonstrated that TGP could reduce the activity of ALT and AST in liver injury and the content of MDA in liver homogenate, increase the activity of SOD and protect drug-induced liver injury [60]. Meanwhile, TGP might protect hepatocytes through modulating oxidative damage improving the changes in liver structure and alleviating lobular necrosis in an acute liver injury rat model. In addition to, the increased expression of iNOS and CYP2E1 in liver of acute liver injury rat model also had been attenuated by TGP [61]. Those may be the reasons why TGP plus LEF (and MTX) therapy decreased the incidence of hepatic adverse effect compared to LEF (and MTX) therapy, but it requires further research and definite evidence. 


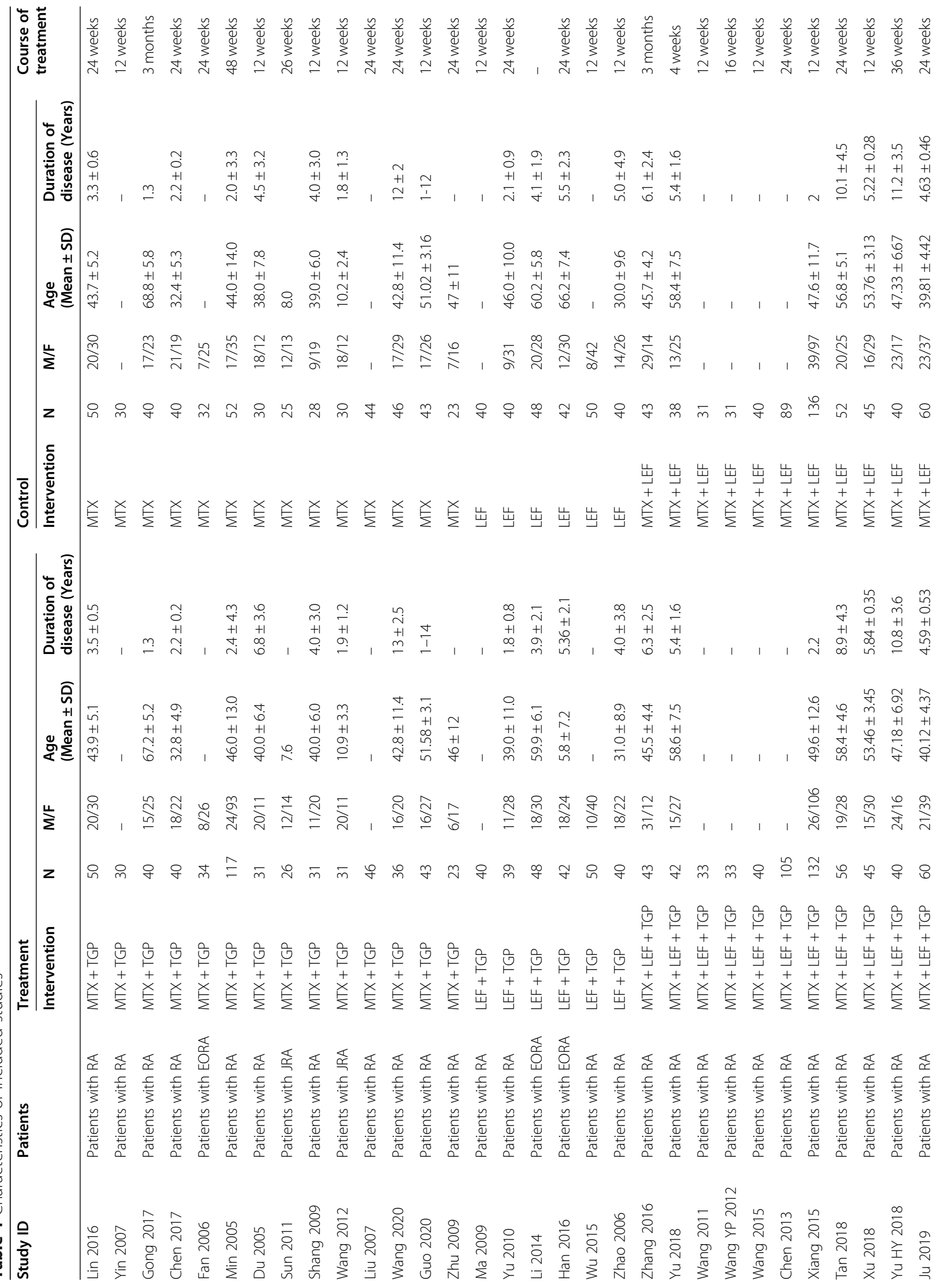




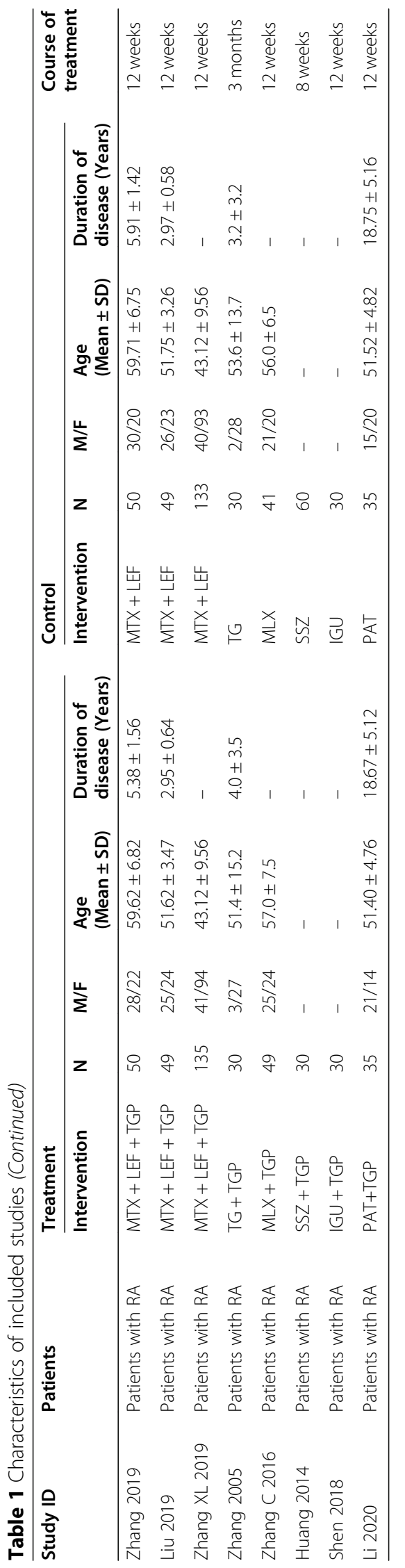




\begin{tabular}{|c|c|c|c|c|c|c|c|c|c|}
\hline \multirow[b]{2}{*}{ Study or Subgroup } & \multicolumn{2}{|c|}{ Experimental } & \multicolumn{2}{|c|}{ Control } & & \multirow{2}{*}{$\begin{array}{c}\text { Risk Ratio } \\
\text { M-H, Fixed, } 95 \% \mathrm{Cl}\end{array}$} & \multirow{2}{*}{\multicolumn{3}{|c|}{$\begin{array}{c}\text { Risk Ratio } \\
\text { M-H, Fixed, } 95 \% \mathrm{Cl}\end{array}$}} \\
\hline & Events & Total & Events & Total & Weight & & & & \\
\hline \multicolumn{10}{|c|}{ 1.1.1 MTX+TGP VS MTX } \\
\hline Guo 2020 & 1 & 43 & 0 & 43 & $0.3 \%$ & $3.00[0.13,71.65]$ & & & \\
\hline Lin 2016 & 0 & 50 & 2 & 50 & $1.4 \%$ & $0.20[0.01,4.06]$ & & & \\
\hline Liu 2007 & 1 & 46 & 5 & 44 & $2.9 \%$ & $0.19[0.02,1.57]$ & & - & \\
\hline Min 2005 & 3 & 117 & 1 & 52 & $0.8 \%$ & $1.33[0.14,12.52]$ & & & \\
\hline Zhu 2009 & 0 & 23 & 2 & 23 & $1.4 \%$ & $0.20[0.01,3.95]$ & & & \\
\hline Subtotal $(95 \% \mathrm{Cl})$ & & 279 & & 212 & $6.7 \%$ & $0.44[0.16,1.22]$ & & & \\
\hline Total events & 5 & & 10 & & & & & & \\
\hline \multicolumn{10}{|c|}{ Heterogeneity: $\mathrm{Chi}^{2}=3.48, \mathrm{df}=4(P=0.48) ; \mathrm{I}^{2}=0 \%$} \\
\hline \multicolumn{10}{|c|}{ Test for overall effect: $Z=1.58(P=0.11)$} \\
\hline \multicolumn{10}{|l|}{ 1.1.2 LEF+TGP VS LEF } \\
\hline Han 2016 & 1 & 42 & 2 & 42 & $1.1 \%$ & $0.50[0.05,5.31]$ & & & \\
\hline Li 2014 & 0 & 48 & 2 & 48 & $1.4 \%$ & $0.20[0.01,4.06]$ & & & \\
\hline Ma 2009 & 0 & 40 & 3 & 40 & $2.0 \%$ & $0.14[0.01,2.68]$ & & & \\
\hline Wu 2015 & 2 & 50 & 10 & 50 & $5.6 \%$ & $0.20[0.05,0.87]$ & & & \\
\hline Yu 2010 & 0 & 39 & 2 & 40 & $1.4 \%$ & $0.20[0.01,4.14]$ & & & \\
\hline Subtotal $(95 \% \mathrm{Cl})$ & & 219 & & 220 & $11.5 \%$ & $0.22[0.08,0.60]$ & & & \\
\hline Total events & 3 & & 19 & & & & & & \\
\hline \multicolumn{10}{|c|}{ Heterogeneity: $\mathrm{Chi}^{2}=0.57, \mathrm{df}=4(\mathrm{P}=0.97) ; \mathrm{I}^{2}=0 \%$} \\
\hline \multicolumn{10}{|c|}{ Test for overall effect: $Z=2.97(P=0.003)$} \\
\hline \multicolumn{10}{|c|}{ 1.1.3 MTX+LEF+TGP VS MTX+LEF } \\
\hline Chen 2013 & 10 & 105 & 31 & 89 & $18.9 \%$ & $0.27[0.14,0.53]$ &  & & \\
\hline Ju 2019 & 6 & 60 & 22 & 60 & $12.4 \%$ & $0.27[0.12,0.62]$ & 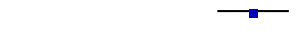 & & \\
\hline Liu 2019 & 1 & 49 & 6 & 49 & $3.4 \%$ & $0.17[0.02,1.33]$ & & & \\
\hline Tan 2018 & 2 & 56 & 5 & 52 & $2.9 \%$ & $0.37[0.08,1.83]$ & & & \\
\hline Wang 2011 & 2 & 33 & 9 & 31 & $5.2 \%$ & $0.21[0.05,0.89]$ & & & \\
\hline Wang 2015 & 1 & 40 & 4 & 40 & $2.2 \%$ & $0.25[0.03,2.14]$ & & & \\
\hline Wang YP 2012 & 2 & 33 & 9 & 31 & $5.2 \%$ & $0.21[0.05,0.89]$ & & & \\
\hline Xiang 2015 & 14 & 132 & 30 & 136 & $16.6 \%$ & $0.48[0.27,0.87]$ & $\longrightarrow$ & & \\
\hline Yu HY 2018 & 0 & 40 & 5 & 40 & $3.1 \%$ & $0.09[0.01,1.59]$ & & & \\
\hline Zhang XL 2019 & 5 & 135 & 15 & 135 & $8.4 \%$ & $0.33[0.12,0.89]$ & 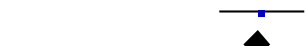 & & \\
\hline Subtotal $(95 \% \mathrm{Cl})$ & & 683 & & 663 & $78.4 \%$ & $0.31[0.22,0.42]$ &  & & \\
\hline Total events & 43 & & 136 & & & & & & \\
\hline \multicolumn{10}{|c|}{ Heterogeneity: $\mathrm{Chi}^{2}=4.13, \mathrm{df}=9(\mathrm{P}=0.90) ; \mathrm{I}^{2}=0 \%$} \\
\hline \multicolumn{10}{|c|}{ Test for overall effect: $Z=7.25(P<0.00001)$} \\
\hline \multicolumn{10}{|c|}{ 1.1.4 SSZ+TGP VS SSZ } \\
\hline Huang 2014 & 1 & 30 & 3 & 60 & $1.1 \%$ & $0.67[0.07,6.14]$ & & & \\
\hline Subtotal $(95 \% \mathrm{Cl})$ & & 30 & & 60 & $1.1 \%$ & $0.67[0.07,6.14]$ & & & \\
\hline Total events & 1 & & 3 & & & & & & \\
\hline \multicolumn{10}{|c|}{ Heterogeneity: Not applicable } \\
\hline \multicolumn{10}{|c|}{ Test for overall effect: $Z=0.36(P=0.72)$} \\
\hline \multicolumn{10}{|l|}{ 1.1.5 IGU+TGP VS IGU } \\
\hline Shen 2018 & 1 & 30 & 4 & 30 & $2.2 \%$ & $0.25[0.03,2.11]$ & & - & \\
\hline Subtotal $(95 \% \mathrm{Cl})$ & & 30 & & 30 & $2.2 \%$ & $0.25[0.03,2.11]$ & & & \\
\hline Total events & 1 & & 4 & & & & & & \\
\hline Heterogeneity: Not ap & licable & & & & & & & & \\
\hline Test for overall effect: & $Z=1.27(P$ & $=0.20)$ & & & & & & & \\
\hline Total $(95 \% \mathrm{Cl})$ & & 1241 & & 1185 & $100.0 \%$ & $0.31[0.23,0.41]$ & $\nabla$ & & \\
\hline Total events & 53 & & 172 & & & & & & \\
\hline Heterogeneity: $\mathrm{Chi}^{2}=$ & $9.50, d f=2$ & $1(P=0$. & $98) ; 1^{2}=0$ & & & & & 110 & 1000 \\
\hline $\begin{array}{l}\text { Test for overall effect: } \\
\text { Test for subgroup diff }\end{array}$ & $\begin{array}{l}Z=8.07(P \\
\text { rences: Ch }\end{array}$ & $\begin{array}{l}<0.000 \\
i^{2}=1.44\end{array}$ & df $=4(P$ & & $34), I^{2}=0 \%$ & & Favours [experimental] & Favours [control] & 1000 \\
\hline
\end{tabular}

In this meta-analysis, TGP adjuvant therapy can decrease the incidence of leukopenia, but no statistical difference was found in the subgroups. Meanwhile, TGP is effective and safety in treatment patients of leukopenia with systemic lupus erythematosus [62]. Although there was no statistical significance in gastrointestinal adverse effect, cutaneous adverse effect and nervous system adverse effect, a certain 


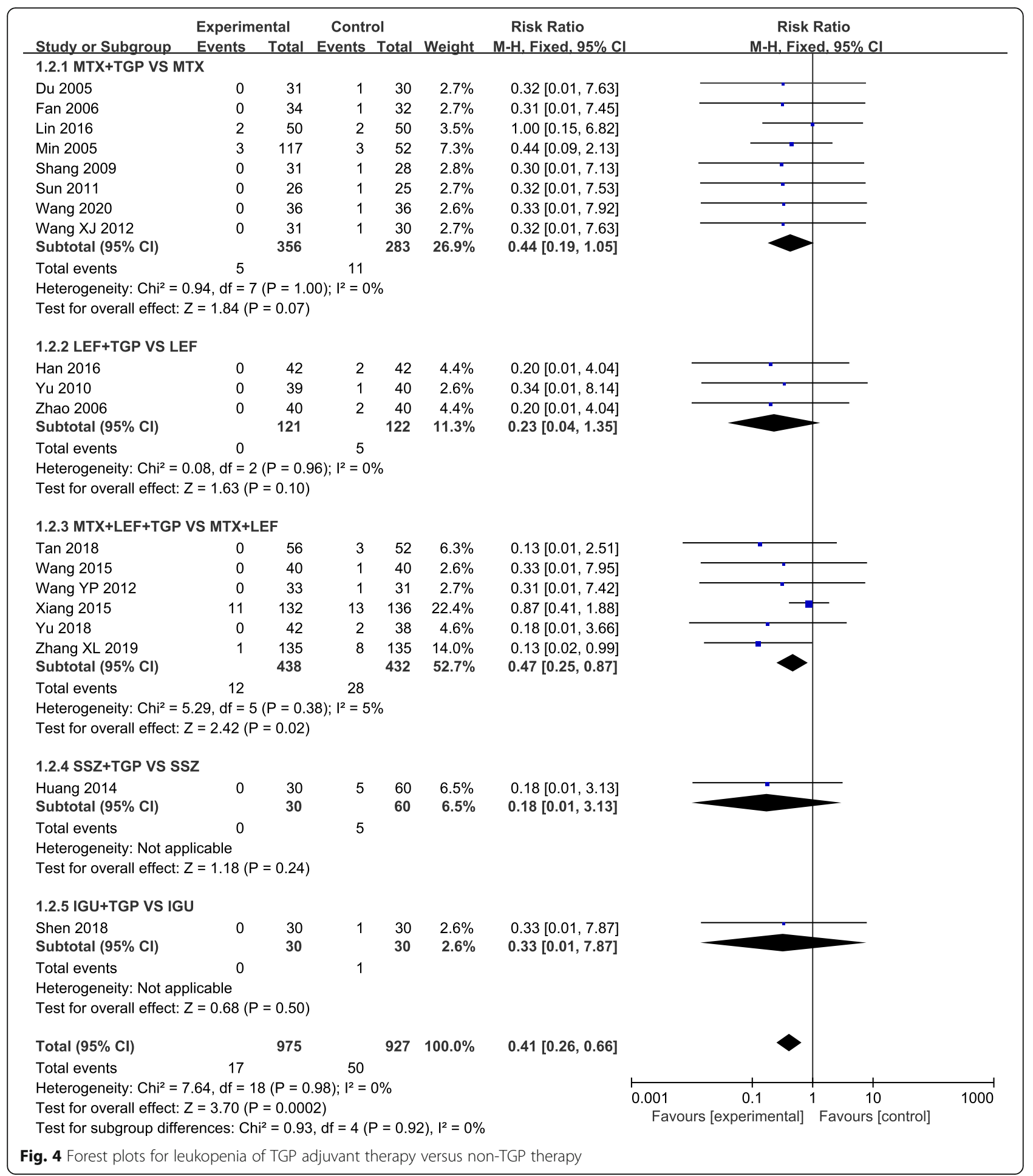

downward trend showed in the incidence of these adverse effects.

This review has several limitations. Firstly, almost all trials had focused on therapeutic effect, and there were a few trials focused on clinical safety evaluation specifically, so the sample of raw data included in this review was small. Although we searched the Chinese and English databases, all the included trials were conducted in China, which may have introduced potential selection bias and limited the external promotion of the evidence. Secondly, the purity, concentrations, quality control and chemical analysis of TGP were not presented in all the 


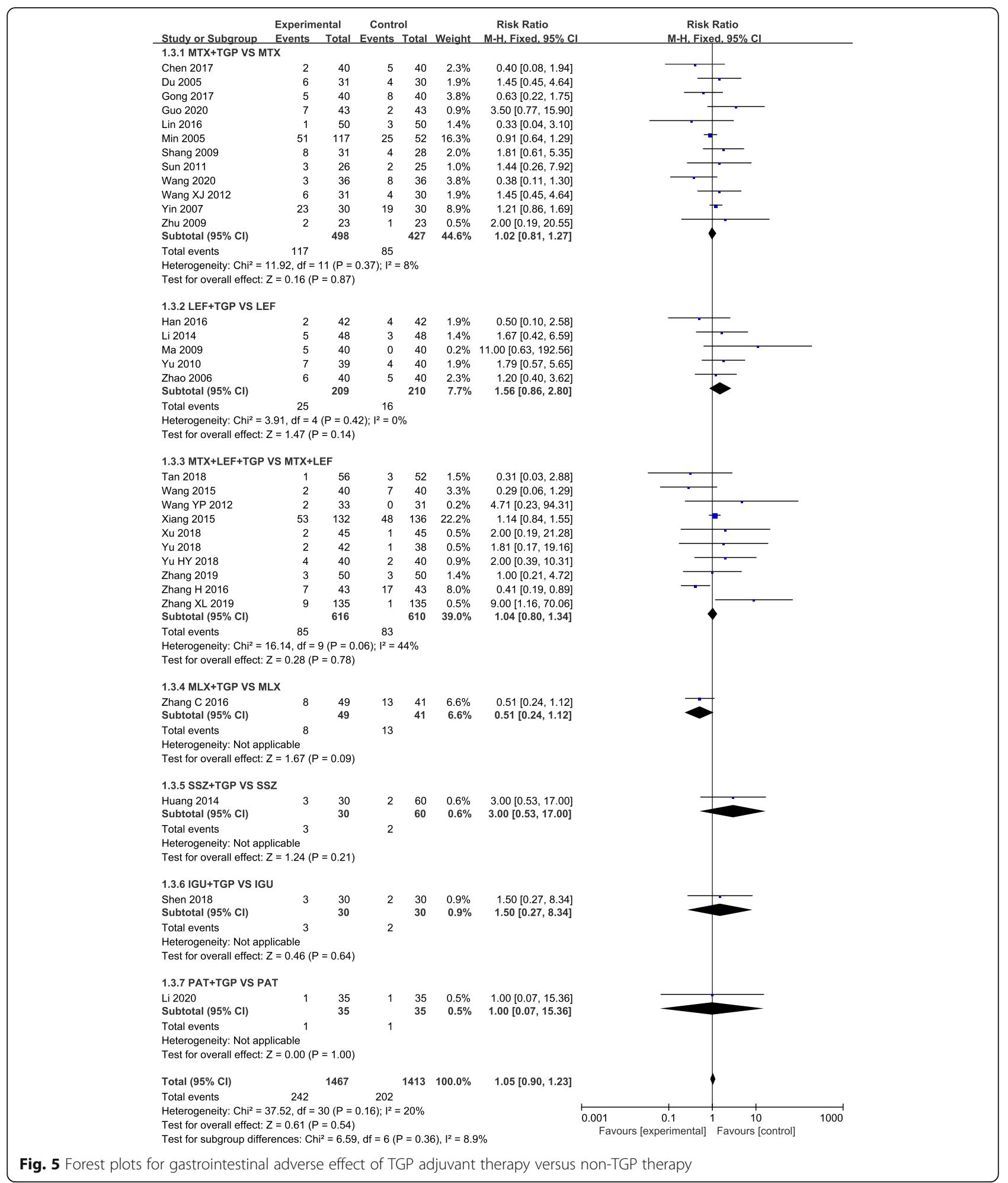

original studies. Thirdly, clinical safety may not be sufficient for safety of drug, since the herbal extracts were used together with western medications thus herb-drug interaction should also be considered and evaluated. In fact, we searched the literature about herb-drug interaction of TGP and the other herbal extracts, but literatures is rare, which may also be a limitation of this study. This is something we need to further study in the future. Although the limitations mentioned above may undermine the level of 


\begin{tabular}{|c|c|c|c|c|c|c|c|c|c|c|}
\hline Study or Subgroup & \multicolumn{2}{|c|}{ Experimental } & \multicolumn{2}{|c|}{ Control } & Weight & $\begin{array}{c}\text { Risk Ratio } \\
\text { M-H, Fixed, } 95 \% \mathrm{Cl}\end{array}$ & \multicolumn{4}{|c|}{$\begin{array}{c}\text { Risk Ratio } \\
\text { M-H, Fixed, } 95 \% \mathrm{Cl}\end{array}$} \\
\hline \multicolumn{11}{|c|}{ 1.4.1 MTX+TGP VS MTX } \\
\hline Chen 2017 & 1 & 40 & 1 & 40 & $2.8 \%$ & $1.00[0.06,15.44]$ & & & & \\
\hline Du 2005 & 0 & 31 & 2 & 30 & $7.2 \%$ & $0.19[0.01,3.88]$ & & & & \\
\hline Guo 2020 & 1 & 43 & 1 & 43 & $2.8 \%$ & $1.00[0.06,15.48]$ & & & & \\
\hline Lin 2016 & 5 & 50 & 3 & 50 & $8.5 \%$ & $1.67[0.42,6.60]$ & & & & \\
\hline Min 2005 & 1 & 117 & 2 & 52 & $7.9 \%$ & $0.22[0.02,2.40]$ & & & & \\
\hline Shang 2009 & 0 & 31 & 2 & 28 & $7.4 \%$ & $0.18[0.01,3.62]$ & & & & \\
\hline Sun 2011 & 0 & 26 & 1 & 25 & $4.3 \%$ & $0.32[0.01,7.53]$ & & & & \\
\hline Wang XJ 2012 & 0 & 31 & 2 & 30 & $7.2 \%$ & $0.19[0.01,3.88]$ & & & & \\
\hline Subtotal $(95 \% \mathrm{Cl})$ & & 369 & & 298 & $48.2 \%$ & $0.56[0.26,1.20]$ & & & & \\
\hline Total events & 8 & & 14 & & & & & & & \\
\hline \multicolumn{11}{|c|}{ Heterogeneity: $\mathrm{Chi}^{2}=4.96, d f=7(P=0.66) ;\left.\right|^{2}=0 \%$} \\
\hline \multicolumn{11}{|c|}{ Test for overall effect: $Z=1.48(P=0.14)$} \\
\hline \multicolumn{11}{|c|}{ 1.4.2 LEF+TGP VS LEF } \\
\hline Han 2016 & 0 & 42 & 1 & 42 & $4.3 \%$ & $0.33[0.01,7.96]$ & & & & \\
\hline Li 2014 & 0 & 48 & 1 & 48 & $4.3 \%$ & $0.33[0.01,7.98]$ & & & & \\
\hline Yu 2010 & 0 & 39 & 2 & 40 & $7.0 \%$ & $0.20[0.01,4.14]$ & & & & \\
\hline Zhao 2006 & 0 & 40 & 2 & 40 & $7.1 \%$ & $0.20[0.01,4.04]$ & & & & \\
\hline Subtotal $(95 \% \mathrm{Cl})$ & & 169 & & 170 & $22.6 \%$ & $0.25[0.05,1.17]$ & & & & \\
\hline Total events & 0 & & 6 & & & & & & & \\
\hline \multicolumn{11}{|c|}{ Heterogeneity: $\mathrm{Chi}^{2}=0.10, \mathrm{df}=3(\mathrm{P}=0.99) ; \mathrm{I}^{2}=0 \%$} \\
\hline \multicolumn{11}{|c|}{ Test for overall effect: $Z=1.76(P=0.08)$} \\
\hline \multicolumn{11}{|c|}{ 1.4.3 MTX+LEF+TGP VS MTX+LEF } \\
\hline Tan 2018 & 3 & 56 & 2 & 52 & $5.9 \%$ & $1.39[0.24,8.01]$ & & & & \\
\hline Wang YP 2012 & 0 & 33 & 1 & 31 & $4.4 \%$ & $0.31[0.01,7.42]$ & & & & \\
\hline Xu 2018 & 1 & 45 & 1 & 45 & $2.8 \%$ & $1.00[0.06,15.50]$ & & & & \\
\hline Yu HY 2018 & 1 & 40 & 1 & 40 & $2.8 \%$ & $1.00[0.06,15.44]$ & & & & \\
\hline Zhang 2019 & 1 & 50 & 0 & 50 & $1.4 \%$ & $3.00[0.13,71.92]$ & & & & \\
\hline Zhang H 2016 & 0 & 43 & 1 & 43 & $4.3 \%$ & $0.33[0.01,7.96]$ & & & & \\
\hline Subtotal $(95 \% \mathrm{Cl})$ & & 267 & & 261 & $21.6 \%$ & $0.97[0.36,2.63]$ & & & & \\
\hline Total events & 6 & & 6 & & & & & & & \\
\hline \multicolumn{11}{|c|}{ Heterogeneity: $\mathrm{Chi}^{2}=1.58, \mathrm{df}=5(P=0.90) ;\left.\right|^{2}=0 \%$} \\
\hline \multicolumn{11}{|c|}{ Test for overall effect: $Z=0.06(P=0.95)$} \\
\hline \multicolumn{11}{|c|}{ 1.4.4 MLX+TGP VS MLX } \\
\hline Zhang C 2016 & 1 & 49 & 2 & 41 & $6.2 \%$ & $0.42[0.04,4.45]$ & & & & \\
\hline $\begin{array}{l}\text { Subtotal }(95 \% \mathrm{Cl}) \\
\text { Total events }\end{array}$ & 1 & 49 & 2 & 41 & $6.2 \%$ & $0.42[0.04,4.45]$ & & & & \\
\hline \multicolumn{11}{|c|}{ Heterogeneity: Not applicable } \\
\hline \multicolumn{11}{|c|}{ Test for overall effect: $Z=0.72(P=0.47)$} \\
\hline 1.4.5 PAT+TGP VS F & & & & & & & & & & \\
\hline Li 2020 & 1 & 35 & 0 & 35 & $1.4 \%$ & $3.00[0.13,71.22]$ & & & & \\
\hline Subtotal $(95 \% \mathrm{Cl})$ & & 35 & & 35 & $1.4 \%$ & $3.00[0.13,71.22]$ & & & & \\
\hline Total events & 1 & & 0 & & & & & & & \\
\hline Heterogeneity: Not ap & licable & & & & & & & & & \\
\hline Test for overall effect & $Z=0.68(P$ & $=0.50)$ & & & & & & & & \\
\hline Total $(95 \% \mathrm{Cl})$ & & 889 & & 805 & $100.0 \%$ & $0.61[0.36,1.02]$ & & & & \\
\hline Total events & 16 & & 28 & & & & & & & \\
\hline Heterogeneity: $\mathrm{Chi}^{2}=$ & $9.68, \mathrm{df}=1$ & $9(P=0$ & $.96) ; 1^{2}=0$ & & & & & & 110 & 1000 \\
\hline Test for overall effect & $Z=1.88(F$ & $=0.06)$ & & & & & $\begin{array}{l}0.001 \\
\text { Fav }\end{array}$ & jours [experimental] & Favours [control] & 1000 \\
\hline Test for subgroup diff & rences: $\mathrm{Cr}$ & $j^{2}=3.21$ & $1, d f=4(P$ & $=0.5$ & $2), I^{2}=0 \%$ & & & & & \\
\hline ig. 6 Forest plots for & dtaneous a & dverse e & effect of Tc & GP adj & juvant ther & rapy versus non-TC & thera & & & \\
\hline
\end{tabular}

evidence of this meta-analysis, the selected trials are highly comparable, and the documents were selected in strict accordance with inclusion criteria. To some extent, the safety data from these trials also provided us with some research directions.
This review indicates that high quality studies would be warranted to confirm the clinical safety. First, clinical trial protocols should be predetermined based on research questions and registered to ensure that research can be conducted according to 


\begin{tabular}{|c|c|c|c|c|c|c|c|c|c|}
\hline \multirow[b]{2}{*}{ Study or Subgroup } & \multicolumn{2}{|c|}{ Experimental } & \multicolumn{2}{|c|}{ Control } & & Risk Ratio & \multirow{2}{*}{\multicolumn{3}{|c|}{$\begin{array}{c}\text { Risk Ratio } \\
\text { M-H, Fixed, } 95 \% \mathrm{Cl}\end{array}$}} \\
\hline & Events & Total & Events & Total & Weight & M-H, Fixed, $95 \% \mathrm{Cl}$ & & & \\
\hline \multicolumn{10}{|c|}{ 1.5.1 MTX+TGP VS MTX } \\
\hline Du 2005 & 1 & 31 & 2 & 30 & $10.1 \%$ & $0.48[0.05,5.06]$ & & & \\
\hline Gong 2017 & 1 & 40 & 2 & 40 & $9.9 \%$ & $0.50[0.05,5.30]$ & & & \\
\hline Lin 2016 & 2 & 50 & 1 & 50 & $5.0 \%$ & $2.00[0.19,21.36]$ & & & \\
\hline Shang 2009 & 1 & 31 & 2 & 28 & $10.4 \%$ & $0.45[0.04,4.71]$ & & & \\
\hline Sun 2011 & 1 & 26 & 0 & 25 & $2.5 \%$ & $2.89[0.12,67.75]$ & & & \\
\hline Wang XJ 2012 & 1 & 31 & 2 & 30 & $10.1 \%$ & $0.48[0.05,5.06]$ & & & \\
\hline Subtotal $(95 \% \mathrm{Cl})$ & & 209 & & 203 & $48.1 \%$ & $0.76[0.30,1.95]$ & & & \\
\hline Total events & 7 & & 9 & & & & & & \\
\hline \multicolumn{10}{|c|}{ Heterogeneity: $\mathrm{Chi}^{2}=1.92, \mathrm{df}=5(\mathrm{P}=0.86) ; \mathrm{I}^{2}=0 \%$} \\
\hline \multicolumn{10}{|c|}{ Test for overall effect: $Z=0.56(P=0.57)$} \\
\hline \multicolumn{10}{|c|}{ 1.5.2 LEF+TGP VS LEF } \\
\hline Yu 2010 & 0 & 39 & 1 & 40 & $7.4 \%$ & $0.34[0.01,8.14]$ & & & \\
\hline Zhao 2006 & 2 & 40 & 2 & 40 & $9.9 \%$ & $1.00[0.15,6.76]$ & & & \\
\hline Subtotal $(95 \% \mathrm{CI})$ & & 79 & & 80 & $17.3 \%$ & $0.72[0.15,3.54]$ & & & \\
\hline Total events & 2 & & 3 & & & & & & \\
\hline \multicolumn{10}{|c|}{ Heterogeneity: $\mathrm{Chi}^{2}=0.33, \mathrm{df}=1(\mathrm{P}=0.57) ; \mathrm{I}^{2}=0 \%$} \\
\hline \multicolumn{10}{|c|}{ Test for overall effect: $Z=0.40(P=0.69)$} \\
\hline \multicolumn{10}{|c|}{ 1.5.3 MTX+LEF+TGP VS MTX+LEF } \\
\hline Xiang 2015 & 3 & 132 & 3 & 136 & $14.7 \%$ & $1.03[0.21,5.01]$ & & & \\
\hline Zhang XL 2019 & 3 & 135 & 4 & 135 & $19.9 \%$ & $0.75[0.17,3.29]$ & & & \\
\hline Subtotal $(95 \% \mathrm{CI})$ & & 267 & & 271 & $34.6 \%$ & $0.87[0.30,2.55]$ & & & \\
\hline Total events & 6 & & 7 & & & & & & \\
\hline \multicolumn{10}{|c|}{ Heterogeneity: $\mathrm{Chi}^{2}=0.08, \mathrm{df}=1(\mathrm{P}=0.77) ; \mathrm{I}^{2}=0 \%$} \\
\hline \multicolumn{10}{|c|}{ Test for overall effect: $Z=0.26(P=0.80)$} \\
\hline Total $(95 \% \mathrm{Cl})$ & & 555 & & 554 & $100.0 \%$ & $0.79[0.42,1.51]$ & & & \\
\hline Total events & 15 & & 19 & & & & & & \\
\hline \multicolumn{7}{|c|}{ Heterogeneity: $\mathrm{Chi}^{2}=2.38, \mathrm{df}=9(P=0.98) ;\left.\right|^{2}=0 \%$} & & 10 & 1000 \\
\hline \multicolumn{7}{|c|}{ Test for overall effect: $Z=0.71(P=0.48)$} & $\begin{array}{c}0.001 \\
\text { Favours [experimental] }\end{array}$ & Favours [control] & \\
\hline \multicolumn{10}{|c|}{ Test for subgroup differences: $\mathrm{Chi}^{2}=0.05, \mathrm{df}=2(P=0.98), \mathrm{I}^{2}=0 \%$} \\
\hline
\end{tabular}

predetermined criteria. Meanwhile, factors that may influence or reduce the quality of the research methodology should be controlled during the research process. Appropriate methods are needed to generate random numbers, assign hidden, lose data processing, and avoid performance biases and other biases. In addition, statistics and observations of clinical data are required to unify the outcomes of clinical safety.

\section{Conclusions}

This meta-analysis indicated that TGP adjuvant therapy might alleviate the incidence of hepatic adverse effect and leukopenia for the RA treatment compared to nonTGP therapy. Further large sample, multicenter, highquality studies are still needed to confirm the clinical safety of TGP adjuvant therapy.

\section{Supplementary Information}

The online version contains supplementary material available at https://doi. org/10.1186/s12906-021-03252-y.

Additional file 1. The detailed search strategies.

\section{Abbreviations}

TGP: Total glucosides of paeony; RA: Rheumatoid arthritis; RCTs: Randomized controlled trials; RR: Risk ratio; Cl: Confidence interval; MTX: Methotrexate;

LEF: Leflunomide; TG: Tripterygium glycosides; MLX: Meloxicam;

SSZ: Sulfasalazine; ALT: Transaminase; AST: Aspartate transaminase;

IGU: Iguratimod; PAT: Prednisone acetate tablets

Acknowledgements

Not applicable.

Authors' contributions

$\mathrm{CL}, \mathrm{YC}$ and $\mathrm{YW}$ contributed to design of the review. $\mathrm{XM}$ and $\mathrm{YM}$ contributed in study search and selection. BL and $\mathrm{HL}$ contributed in data extraction and analysis. BL and XM wrote the manuscript. YM, YL and NS critically edited the manuscript. All authors approved the final version to be published.

\section{Funding}

The study was supported by the Special Research Project of the 13th FiveYear Plan of China Academy of Chinese Medical Sciences (Grant No ZZ10009), the 11th batch of key projects of the Institute of Basic Research in Traditional Chinese Medicine, China Academy of Chinese Medical Sciences (Grant No Z0545), national Administration of Traditional Chinese Medicine (Grant No GZY-FJS-2017-62), the 12th batch of independent topics selected by the Institute of Traditional Chinese Medicine Clinical Basic Medicine of China Academy of Chinese Medical Sciences (Grant No Z0604) and National Natural Science Foundation of China (Grant No 81703949). The funding bodies play no role in the design of the study and collection, analysis, and interpretation of data and in writing the manuscript. 


\section{Availability of data and materials}

All data generated during this study are included in this article and its supplementary information files.

\section{Ethics approval and consent to participate}

This study was based on previously published studies; therefore, ethical approval and patient consent are not relevant.

\section{Consent for publication}

Not applicable.

\section{Competing interests}

The authors declare that they have no competing interests.

\section{Author details}

${ }^{1}$ Institute of Basic Research in Clinical Medicine, China Academy of Chinese Medical Sciences, Beijing, China. ${ }^{2}$ Evidence-Based Medicine Center, School of Basic Medical Sciences, Lanzhou University, Lanzhou, China. ${ }^{3} \mathrm{WHO}$ Collaborating Centre for Guideline Implementation and Knowledge Translation, Lanzhou University, Lanzhou, China. ${ }^{4}$ Chinese GRADE Center, Lanzhou, China.

Received: 9 October 2019 Accepted: 17 February 2021

Published online: 26 March 2021

\section{References}

1. Smolen JS, Aletaha D, Mclnnes IB. Rheumatoid arthritis. Lancet (London, England). 2016;388(10055):2023-38.

2. Guo Q, Wang Y, Xu D, Nossent J, Pavlos NJ, Xu J. Rheumatoid arthritis: pathological mechanisms and modern pharmacologic therapies. Bone Res. 2018:6:15

3. Zampeli E, Vlachoyiannopoulos PG, Tzioufas AG. Treatment of rheumatoid arthritis: unraveling the conundrum. J Autoimmun. 2015:65:1-18.

4. Wang W, Zhou H, Liu L. Side effects of methotrexate therapy for rheumatoid arthritis: a systematic review. Eur J Med Chem. 2018:158:502-16.

5. Rasch LA, Bultink IE, van Tuyl LH, Lems WF. Glucocorticoid safety for treating rheumatoid arthritis. Expert Opin Drug Saf. 2015;14(6):839-44.

6. Soukup T, Dosedel M, Nekvindova J, Toms J, Vlcek J, Pavek P. Genetic polymorphisms in metabolic pathways of leflunomide in the treatment of rheumatoid arthritis. Clin Exp Rheumatol. 2015:33(3):426-32.

7. Wongrakpanich S, Wongrakpanich A, Melhado K, Rangaswami J. A comprehensive review of non-steroidal anti-inflammatory drug use in the elderly. Aging Dis. 2018;9(1):143-50

8. van Hasselt J, lyengar R. Systems pharmacology: defining the interactions of drug combinations. Annu Rev Pharmacol Toxicol. 2019;59:21-40.

9. Spinks J, Johnston D, Hollingsworth B. Complementary and alternative medicine (CAM) use and quality of life in people with type 2 diabetes and/ or cardiovascular disease. Complement Ther Med. 2014:22(1):107-15.

10. Jiang H, Li J, Wang L, Wang S, Nie X, Chen Y, Fu Q, Jiang M, Fu C, He Y. Total glucosides of paeony: a review of its phytochemistry, role in autoimmune diseases, and mechanisms of action. J Ethnopharmacol. 2020; 258:112913.

11. Fernandez-Ruiz D, Ng WY, Holz LE, Ma JZ, Zaid A, Wong YC, Lau LS, Mollard V, Cozijnsen A, Collins N, et al. Liver-resident memory CD8(+) T cells form a frontline defense against malaria liver-stage infection. Immunity. 2019;51(4):780.

12. Zhou J, Peng H, Li K, Qu K, Wang B, Wu Y, Ye L, Dong Z, Wei H, Sun R, et al. Liver-resident NK cells control antiviral activity of hepatic T cells via the PD1-PD-L1 Axis. Immunity. 2019;50(2):403-17.

13. Zhang W, Dai SM. Mechanisms involved in the therapeutic effects of Paeonia lactiflora Pallas in rheumatoid arthritis. Int Immunopharmacol. 2012; 14(1):27-31.

14. Xu W, Zhao Y, Qin Y, Ge B, Gong W, Wu Y, Li X, Zhao Y, Xu P, Xue M. Enhancement of Exposure and Reduction of Elimination for Paeoniflorin or Albiflorin via Co-Administration with Total Peony Glucosides and Hypoxic Pharmacokinetics Comparison. Molecules. 2016;21(7):874

15. Lin J, Xiao L, Ouyang G, Shen Y, Huo R, Zhou Z, Sun Y, Zhu X, Zhang J, Shen $B$, et al. Total glucosides of paeony inhibits Th1/Th17 cells via decreasing dendritic cells activation in rheumatoid arthritis. Cell Immunol. 2012;280(2):156-63.
16. He DY, Dai SM. Anti-inflammatory and immunomodulatory effects of Paeonia lactiflora pall., a traditional chinese herbal medicine. Front Pharmacol. 2011;2:10.

17. Li H, Cao W, Lu M, Wu C, Wang X, Niu L. Urinary and serum metabolomics analyses uncover that Total Glucosides of Paeony protect liver against acute injury potentially via reprogramming of multiple metabolic pathways. Evid Based Complement Alternat Med. 2017;2017:9038260.

18. Huang Y, Wang H, Chen Z, Wang Y, Qin K, Huang Y, Ba X, Lin W, Tu S. Efficacy and safety of total glucosides of paeony combined with methotrexate and leflunomide for active rheumatoid arthritis: a metaanalysis. Drug Des Devel Ther. 2019;13:1969-84.

19. Li J. Clinical study of total glucosides of paeoniae paeoniae capsule combined with prednisone in the treatment of rheumatoid arthritis. Drugs Clin. 2020;35(4):748-51

20. Wang X, Zhuang M. Efficacy evaluation of total glucosides of paeoniae paeoniae combined with methotrexate in the treatment of rheumatoid arthritis. J China Prescription Drug. 2020;18(11):75-6.

21. Guo X, Tan C. Clinical observation of total glucosides of paeoniae paeoniae combined with methotrexate in the treatment of rheumatoid arthritis. Med J Natl Defending Forces Southwest China. 2020;30(4):301-3.

22. Ju Y, Li R, Guo D, Feng X. Study on protective and adjuvant effect of total glucosides of paeoniae alba on liver function of rheumatoid arthritis. China Modern Doctor. 2019:57(30):34-7.

23. Zhang $\mathrm{H}$, Zhang $\mathrm{W}$. Effect of combination of total glucosides of peony with methotrexate and leflunomide on follicular helper T cells. Acta Medica Mediterr. 2019·35:1239-44.

24. Liu B. Leflunomide and total glucosides of paeoniae paeoniae combined with methotrexate therapy observation on therapeutic effect of rheumatoid arthritis. World Latest Med Inf (Electronic Version). 2019;19(44):134-6.

25. Zhang X. Effect of combined treatment of total glucosides of paeony, methotrexate and leflunomide on WOMAC score in rheumatoid arthritis. Syst Med Pharmacol. 2019:4(6):75-7.

26. Yu W, Xu J, Liang Y, Li M, Sha H. Clinical observation of total paeony glycoside capsule combined with methotrexate and leflunomide in the treatment of rheumatoid arthritis. Sichuan Med J. 2018;39(1):83-5.

27. Tan K, Xiang Y, Yuan L, Dai Y. Clinical observation of total glucosides of paeoniae alba, methotrexate and leflunomide in the treatment of severe active rheumatoid arthritis. World Latest Med Inf (Electronic Version). 2018; 18(6):159-64.

28. Xu P. Clinical effect of total glucosides of paeonia paeoniae combined with methotrexate and leflunomide in the treatment of patients with rheumatoid arthritis. Med Pr. 2018;10:97-9.

29. Yu H, Peng J, Ye X. Efficacy and safety of leflunomide and total glucosides of paeoniae paeoniae combined with methotrexate in the treatment of rheumatoid arthritis. Chin Med Innov. 2018:15(27):8-11.

30. Shen S. Clinical efficacy and safety observation of iguratimod combined with total glycosides of paeoniae paeoniae capsule in RA. Home Med. 2018; 2:160

31. Gong S. Clinical observation of total glucoseides of peony combined methotrexate on rheumatoid arthritis. Strait Pharm J. 2017;29(9):66-8.

32. Chen Z, Liu Q, Liu J, Jiang X, Xue Y. Effect of total glucosides of paeony and methotrexate on refractory rheumatoid arthritis. Journal of Chinese practical diagnosis and therapy. J Chin Pract Diagn Ther. 2017:31(7):700-2.

33. Lin W, Lin Q, Chen R. Effects observation of different treatment program in rheumatoid arthritis. China Modern Med. 2016:23(16):4-7.

34. Han L, GUJANETHAN B, BAYAN E, Shi R, BAKHARGURI L, Wei R. Efficacy of leflunomide combined with total glucosides of peony in elderly patients with rheumatoid arthritis and its effects on ESR,CRP and RF. Chin J Hosp Pharm. 2016;36(7):568-71.

35. Zhang $\mathrm{H}$, Fan $\mathrm{H}$. Efficacy of total glucosides of paeonia on blood lipid in patients with rheumatoid arthritis. Chin J Clin Pharmacol. 2016;32(7):597-9.

36. Zhang C. Clinical observation on treating 90 cases of atrophic arthritis with meloxicam plus Total Glucosides of Paeony capsules. Clin J Chin Med. 2016; 8(4):86-7.

37. Wu T, He R, Liu J, Li Y. The efficacy observation on leflunomide combine with total glucosides of paeony capsules for rheumatoid arthritis. Proc Clin Med. 2015;24(5):342-5

38. Wang $Y$. Therapeutic effect of two combined regimens on rheumatoid arthritis and comparison of liver damage. J Clin Med Lit. 2015;2(11):2132.

39. Xiang N, Li XM, Zhang MJ, Zhao DB, Zhu P, Zuo XX, Yang M, Su Y, Li ZG, Chen $Z$, et al. Total glucosides of paeony can reduce the hepatotoxicity 
caused by methotrexate and Leflunomide combination treatment of active rheumatoid arthritis. Int Immunopharmacol. 2015;28(1):802-7.

40. Li M. The clinical efficacy of leflunomide combined with TGP in the treatment of elderly rheumatoid arthritis and its effect on C-reactive protein and erythrocyte sedimentation rate. China Foreign Med Treat. 2014;33(33):45-7.

41. Huang Y. Clinical observation of treatment of rheumatoid arthritis with sulfasalazine and sulfasalazine combined with total glucosides of paeony. J Med Inform. 2014;27(5):419-20.

42. Chen Z, Li XP, Li Z, Xu L, Li XM. Reduced hepatotoxicity by total glucosides of paeony in combination treatment with leflunomide and methotrexate for patients with active rheumatoid arthritis. Int Immunopharmacol. 2013;15(3):474-7.

43. Wang X. Clinical observation of methotrexate combined with total glucosides of paeony for juvenile rheumatoid arthritis evaluation and analysis of drug-use in hospitals of China. Eval Anal Drug Use Hosp China. 2012;12(8):722-4.

44. Wang Y. Effect of total glucosides of paeoniae paeoniae combined with immunosuppressant in the treatment of rheumatoid arthritis on liver function. Med Forum. 2012;16(13):1644-6.

45. Sun Y. Comparative study on clinical efficacy of using methotrexate singly or combined with total glucosides of paeony in treating juvenile rheumatoid arthritis. J Taishan Med Coll. 2011:32(10):744-6.

46. Wang Y, Li J, Li X. Comparison of efficacy and safety of Total Glucosides of Paeony combined with methotrexate and leflunomind in the treatment of rheumatoid arthritis. Natl Med Front China. 2011;6(19):16-7.

47. Yu J, Zhang H. Clinical study of total glucosides of paeony combined with leflunomide in the treatment of active rheumatoid arthritis. Forum Tradit Chin Med. 2010;25(4):9-10.

48. G S, Liu J. Comparative study on clinical efficacy of methotrexate combined with total glucosides of paeony in the treatment of rheumatoid arthritis. Chin J Clin Ration Drug Use. 2009;2(4):1-4.

49. Ma F. Efficacy and safety of total glucosides of paeony and leflunomide in the treatment of active RA. Liaoning J Tradit Chin Med. 2009;36(9):1509-10.

50. Zhu J. Clinical analysis of metalin combined with total glucosides of paeoniae paeoniae in the treatment of rheumatoid arthritis. Shanxi J Tradit Chin Med. 2009;25:48-9.

51. Yin $\mathrm{G}$, Xie Q. Clinical analysis of the efficacy of total glucosides of paeony capsules on rheumatoid arthritis. Modern Prev Med. 2007;34(19):3791-2.

52. Liu Z. Therapeutic effect of Pavlin combined with methotrexate on rheumatoid arthritis. Chin J Pract Med. 2007:34(3):83-4.

53. Fan Y, Li G. Study of total glucosides of paeony combined with low dosage methotrexate on elderly onset rheumatoid arthritis. Modern J Integr Tradit Chin Western Med. 2006:11:1440-2.

54. Zhao Y, Liu Y. Clinical observation on effects of leflunomid and total glucosides of paeony on rheumatoid arthritis. Chin J Integr Tradit Western Med. 2006;26(4):355-7.

55. Min W, Wei Q, Li H, Zhang Z, Wu L, Yuan G, Dou C, Shi G. A clinical study of total glucosides palony in the treatment of rheumatoid arthritis:a multicenter trial. Chin J Rheumatol. 2005;8:487-91.

56. Du J, Dong B. Comparative study on clinical efficacy of using methotrexate singly or combined with Total Glucosides of Paeony in treating rheumatoid arthritis. Chin J Integr Tradit Western Med. 2005;6:540-2.

57. Zhang L, Zhou Y, Liu W. Clinical efficacy of total glucosides of paeony combined with tripterygium glycosides in the treatment of rheumatoid arthritis. Tianjin J Tradit Chin Med. 2005;3:207-8.

58. Curtis JR, Beukelman T, Onofrei A, Cassell S, Greenberg JD, Kavanaugh A, Reed G, Strand V, Kremer JM. Elevated liver enzyme tests among patients with rheumatoid arthritis or psoriatic arthritis treated with methotrexate and/or leflunomide. Ann Rheum Dis. 2010;69(1):43-7.

59. Bilasy SE, Essawy SS, Mandour MF, Ali EA, Zaitone SA. Myelosuppressive and hepatotoxic potential of leflunomide and methotrexate combination in a rat model of rheumatoid arthritis. Pharmacol Rep. 2015;67(1):102-14.

60. Zheng LY, Pan JQ, LV JH. Effects of total glucosides of paeony on enhancing insulin sensitivity and antagonizing nonalcoholic fatty liver in rats. Zhongguo Zhong Yao Za Zhi. 2008;33(20):2385-90.
61. Qin Y, Tian YP. Protective effects of total glucosides of paeony and the underlying mechanisms in carbon tetrachloride-induced experimental liver injury. Arch Med Sci. 2011;7(4):604-12.

62. Li Z, Liu Y, Chen L, Fan X, Yang K. Clinical observation of Total Glucosides of Paeony to patients of complicated leukopenia with systemic lupus Erythematosus. J Clin Pharm Ther. 2004;4(13):67-8.

\section{Publisher's Note}

Springer Nature remains neutral with regard to jurisdictional claims in published maps and institutional affiliations.

\section{Ready to submit your research? Choose BMC and benefit from:}

- fast, convenient online submission

- thorough peer review by experienced researchers in your field

- rapid publication on acceptance

- support for research data, including large and complex data types

- gold Open Access which fosters wider collaboration and increased citations

- maximum visibility for your research: over $100 \mathrm{M}$ website views per year

At BMC, research is always in progress.

Learn more biomedcentral.com/submissions 